\title{
COMMUNICATION
}

Cite this: DOI: $10.1039 / \mathrm{x} 0 \mathrm{xx} 00000 \mathrm{x}$

\section{Anion Effects to Deliver Enhanced Iridium Catalysts for Hydrogen Isotope Exchange Processes ${ }^{\dagger}$}

\author{
Alan R. Kennedy, ${ }^{a}$ William J. Kerr, ${ }^{* a}$ Rory Moir ${ }^{a}$ and Marc Reid ${ }^{a}$
}

Received 00th January 2012,

Accepted 00th January 2012

DOI: $10.1039 / \mathrm{x} 0 \mathrm{xx} 00000 \mathrm{x}$

www.rsc.org/

Synthesis of a series of iridium(I) complexes of the type [(COD)Ir(IMes) $\left.\left(\mathrm{PPh}_{3}\right)\right] \mathrm{X}\left(\mathrm{X}=\mathrm{BF}_{4}\right.$, OTf, and BArF) has been established. Application of these species in mild hydrogen isotope exchange processes revealed more efficient catalysis and, further, a wider solvent scope when employing larger, more weakly coordinating counterions.

Ionic transition metal complexes play a central role in catalysis and organic synthesis. Although it is more common to tune the properties of such catalysts via manipulation of the coordinated ligands on the transition metal cation, the past two decades have witnessed a significant increase in studies of the effects of changing the negatively charged counterion. ${ }^{1}$ In most cases where the counterion plays a spectator role, moving to larger, more weakly coordinating counterions has evidenced a positive influence on catalyst efficiency across various methodologies, with examples spanning palladium, ${ }^{2}$ rhodium, ${ }^{3}$ and iridium ${ }^{4}$ catalyses, among others. ${ }^{1 \mathrm{a}, \mathrm{b}}$ Having stated this, there also exist some cases in which the ability of the counterion to coordinate to the inner sphere of the transition metal cation is essential for overall structural stability. ${ }^{5}$ Furthermore, changing the counterion has also been documented to completely alter reaction pathways in both transition metal complex synthesis ${ }^{6}$ and organic synthesis. ${ }^{7}$

Our interest in this field stems from the development of cationic iridium(I) $N$-heterocyclic carbene (NHC)-phosphine complexes for pharmaceutically-relevant hydrogen isotope exchange (HIE) processes. $^{8,9}$ To date, we have reported on the development and application of several such complexes, all of which bear the hexafluorophosphate counterion. ${ }^{8 c, 9}$ In this contribution, we report the syntheses and application in HIE of complexes 1b-d, counterion variations of our flagship catalyst, 1a (Fig. 1). ${ }^{9,10}$ As has been demonstrated by Pfaltz and others in iridium-based catalysis, ${ }^{4}$ we hypothesised that moving to larger counterions, such as tetrakis[3,5bis(trifluoromethyl)phenyl] borate (BArF), would enhance the activity

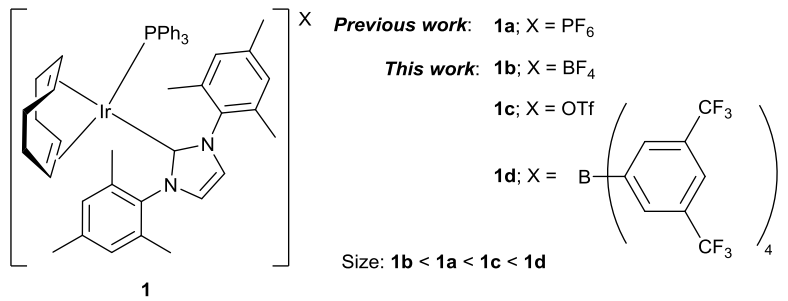

Fig. 1 HIE catalysts bearing different counterions.

and longevity of the proposed new Ir species at lower catalyst loadings. Furthermore, as wider preparative applications of HIE require catalysts operable in a more expansive array of solvent media, ${ }^{8 \mathrm{~d}, 9 \mathrm{~b}, 11}$ we theorised that the more diffuse counterions would enhance the solvent scope of the catalyst beyond that which we have already reported. ${ }^{9}$ To substantiate these proposals, it was necessary to study complexes bearing counterions both larger and smaller than for catalyst $1 \mathbf{a}$.

We began our studies with the syntheses of novel complexes $\mathbf{1 b}$ and 1c, using the general method shown in Table 1. Starting from the chloro-carbene complex, $\mathbf{2},{ }^{12,13}$ the choice of silver salt used to the abstract the chloride ligand simultaneously delivered the counterion of choice (after addition of $\mathrm{PPh}_{3}$ ). Both complexes were isolated in acceptable yields by simple trituration from ethyl acetate.

In turning our attention to the synthesis of complex 1d, the lack of a commercially available source of AgBArF prompted the search for a silver-free synthetic route. In this regard, it was hypothesised that the chloro-carbene intermediate, $\mathbf{2}$, may be circumvented if the parent imidazolium salt required to provide the NHC ligand was partnered with a large and weakly coordinating counterion such as BArF. Indeed, this approach has promising literature precedent relating to iridium complexes bearing a chelating carbene-phosphine ligand. ${ }^{14}$ Accordingly and as detailed in Scheme 1, this approach was successfully realised for 
Table 1 General procedure for the syntheses of complexes $\mathbf{1 b}$ and $\mathbf{1 c}$

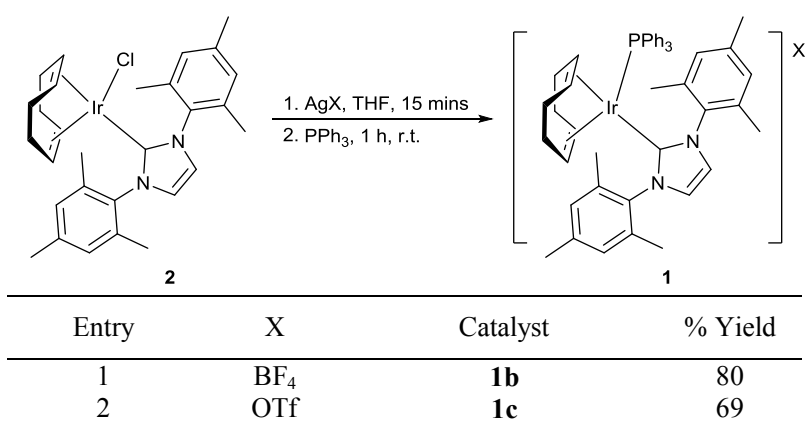

our monodentate NHC-phosphine ligand combination. Firstly, NHC precursor, 4, was synthesised by salt metathesis from 3. Following insitu generation of [(COD) $\left.\operatorname{Ir}\left(\mathrm{PPh}_{3}\right) \mathrm{Cl}\right]$ from 5 and $\mathrm{PPh}_{3}, \mathbf{4}$ was added followed by base to yield the desired complex, 1d, in good yield, and on gram scale.

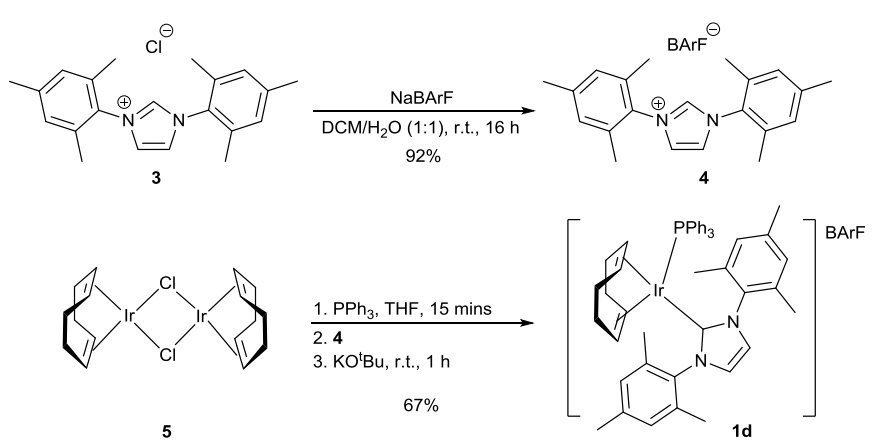

Scheme 1 Silver-free synthesis of complex $1 \mathbf{d}$.

All novel compounds, 1b-d and $\mathbf{4}$, were characterised by NMR $\left({ }^{1} \mathrm{H}\right.$, ${ }^{13} \mathrm{C},{ }^{31} \mathrm{P},{ }^{19} \mathrm{~F}$, and ${ }^{11} \mathrm{~B}$ ), IR, melting point, HRMS, and $\mathrm{X}$-ray crystallography. Of particular note is the $\mathrm{X}$-ray structure determination of complex 1d, which reveals the similar size of the BArF counterion relative to the cationic portion of the complex (Fig. 2).

To investigate the impact of the series of counterions in iridium-based HIE processes, model reactions employing acetophenone, 6, as the substrate were undertaken. In particular, the effect of catalyst loading on the labelling efficacy of complexes 1a-d was scrutinised. As shown

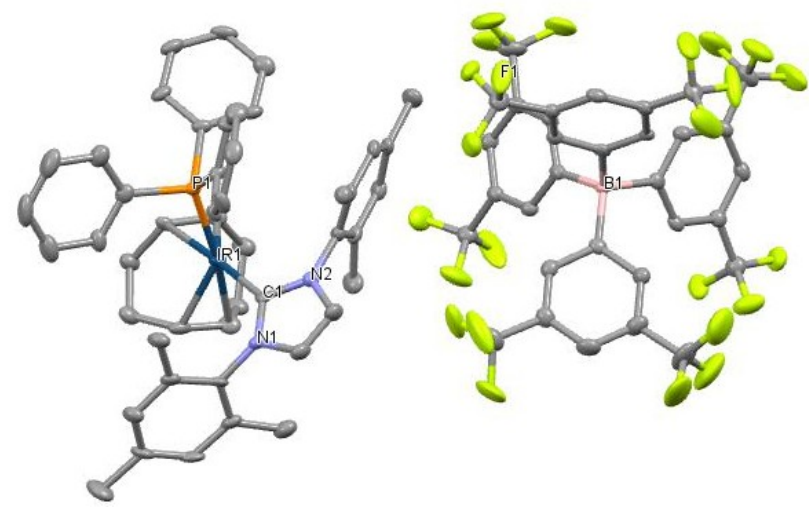

Fig. 2 Molecular structure of catalyst $\mathbf{1 d}$ as determined by X-ray crystallography.

in Scheme 2, the effect of changing the counterion was clearly drawn out at the most accessible and commonly applied reaction temperature of $25{ }^{\circ} \mathrm{C}$. As predicted, the relative efficiency of each catalyst increases in order of increasing counterion volume. ${ }^{15}$ Catalysts $\mathbf{1 c}$ and $\mathbf{1 d}$, bearing the OTf and BArF counterions, respectively, are more active than parent catalyst, $\mathbf{1 a}$, and the catalyst bearing the small $\mathrm{BF}_{4}$ counterion, 1b. Notably, the reactivity of the triflate catalyst, 1c, contrasts with observations made by Pfaltz and co-workers during their study on the counterion effects in olefin hydrogenation using PHOX-type chelating ligands. ${ }^{4 \mathrm{~b}}$ Where these previous studies showed complete shutdown of catalytic activity using the triflate species, we have evidenced that both triflate and BArF counterions perform equally well (and, indeed, better than the parent catalyst, 1a) at $25{ }^{\circ} \mathrm{C}$ within HIE processes. Presumably, this difference in the effectiveness of triflate across these two systems is related to the different orientations of the ancillary ligands in the active catalyst forms. For bidentate PHOX ligands, the coordinating groups adopt a cis configuration, allowing coordination of the dipolar triflate anion to the iridium centre. In catalyst series $\mathbf{1}$, the bulky NHC and phosphine ligands are known to rest trans to one another in the active form. ${ }^{9 c}$ Therefore, triflate coordination may be blocked by the more effective combined steric bulk of a trans NHCphosphine system relative to the more open cis-coordinated PHOX ligands.

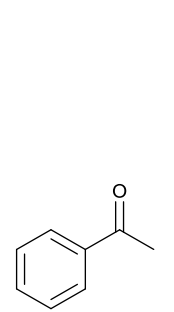

6

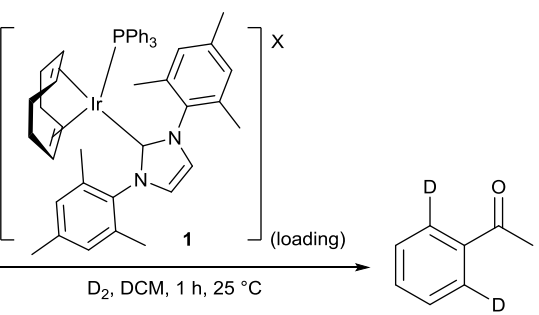

7

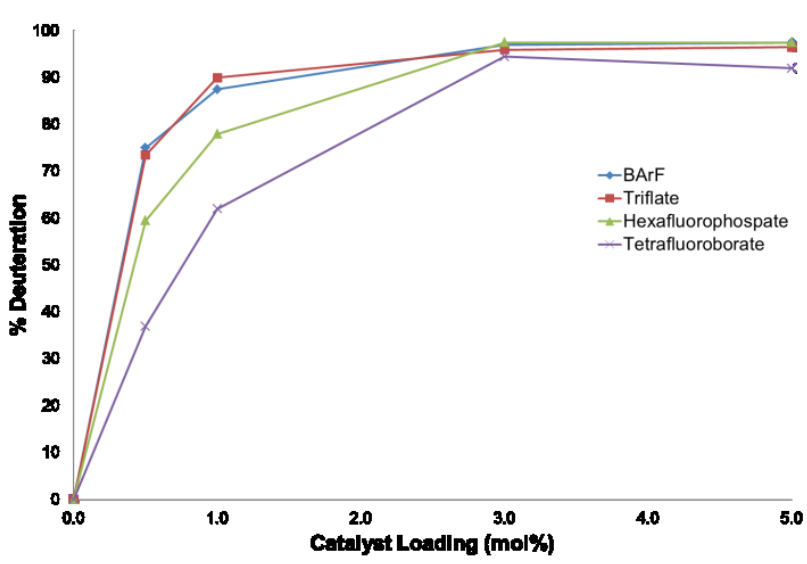

Scheme 2 Assessment of counterion effects on catalyst efficiency.

Next, we explored the effective solvent scope of catalyst 1 with different counterions. Previously, we have identified 2-MeTHF, MTBE, and $\mathrm{Et}_{2} \mathrm{O}$ as viable alternatives to DCM using catalyst 1a. ${ }^{9 \mathrm{~b}}$ Therefore, we compared the applicable solvent scope of 1a versus the most non-polar derivative, 1d, across a wider range of solvents than previously explored. Using the same reference reaction as shown in Scheme 2 ( $5 \mathrm{~mol} \%$ catalyst, $\left.25^{\circ} \mathrm{C}\right)$, we screened a series of ethereal, 
alcoholic, ester, chlorinated, and aromatic solvents. Firstly, we were encouraged to note that the more soluble catalyst, 1d, was generally superior to parent catalyst, 1a, within HIE for the range of ether and carbonate solvents tested (Fig. 3). For dioxane, MTBE, $\mathrm{Et}_{2} \mathrm{O}$, and 2MeTHF both catalysts were shown to perform equally well, with the larger counterion of $\mathbf{1 d}$ offering slight improvements to an already efficient deuteration system. However, more significant improvements were recorded on comparing the activities of $\mathbf{1 a}$ and $\mathbf{1 d}$ in ${ }^{\mathrm{i}} \mathrm{Pr}_{2} \mathrm{O}$, THF, and the recognised green solvents, CPME and dimethyl carbonate. ${ }^{16}$

Alcohol-derived solvents provided a more varied range of reaction efficiencies (Fig. 4). Notably, in all cases, catalyst 1d displayed greater levels of activity and was more widely applicable than 1a. The most significant reactivity from the alcoholic solvents shown was observed in the most sterically shielded (and presumably least coordinating) alcohol, ${ }^{\mathrm{t}} \mathrm{AmOH}$.

A similar pattern of reactivity was observed for ester solvents, and accompanied with higher overall levels of deuterium incorporation (Fig. 4). Again, the combination of catalyst $\mathbf{1 d}$ and the most sterically encumbered solvent ('PrOAc over EtOAc) proved most effective. Chlorinated solvents DCM and DCE evidenced no difference in catalysts 1a and 1d, with both producing almost quantitative Dincorporation. In contrast, a stark difference in deuterium labelling

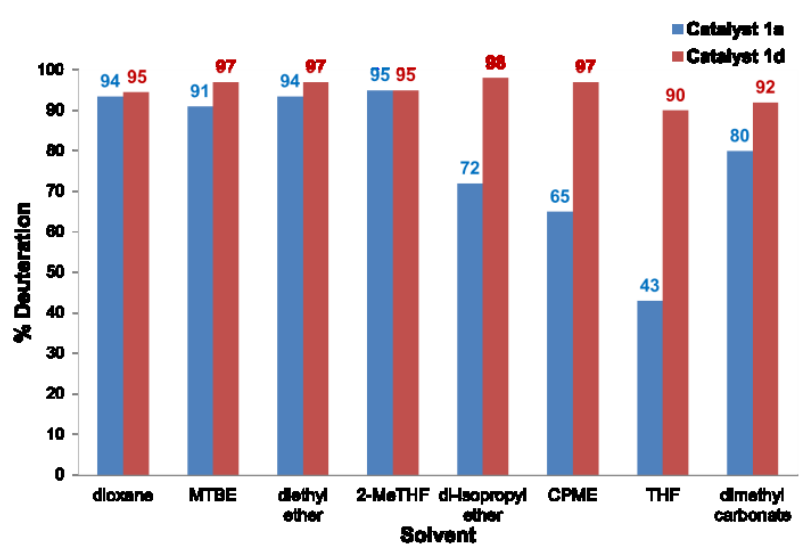

Fig. 3 Counterion influence on ether and carbonate solvent scope. Results are reported as an average of two runs.

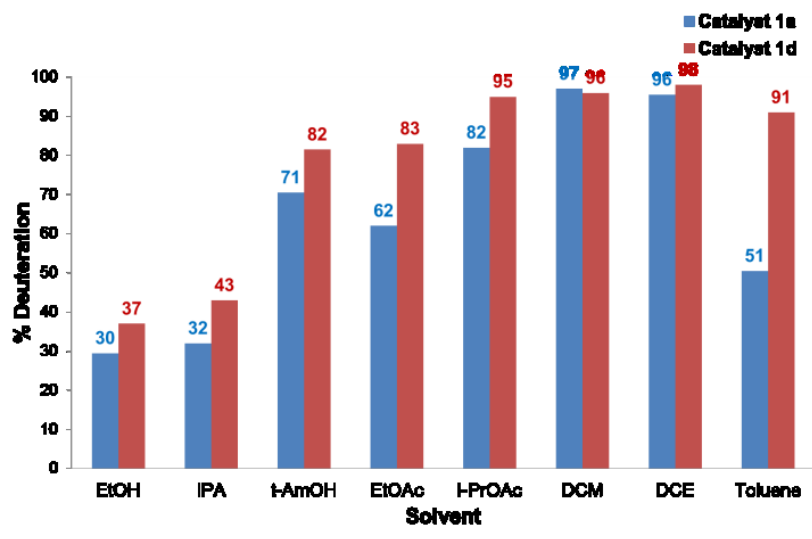

Fig. 4 Counterion influence on alcohol, ester, chlorinated, and aromatic solvent scope. Results are reported as an average of two runs. efficiency was recorded between 1a and 1d when using toluene as the solvent. Again, catalyst 1d was superior to the less soluble catalyst, 1a. Finally, it is also worth noting that more polar solvents DMSO and DMF were tested under the same reaction conditions with complex 1d, however, only very low levels of deuteration in acetophenone were detected (see ESI for results).

As stated in the introduction, owing to the highly variable solubility profile of different drug classes, HIE processes with drug candidates require a flexible solvent choice. To explore the potential benefits of expanded solvent scope with catalyst 1d over 1a, we next turned our attention to the deuterium labelling of drug molecule, Niclosamide, $\mathbf{8}$. Using catalyst 1a or 1d in DCM, similarly moderate to good deuterium incorporation was achieved across all four possible labelling sites (Table 2, Entries 1 and 2). This is presumed to be due to the relative insolubility of $\mathbf{8}$ in DCM. On moving to 2-MeTHF as an alternative solvent (able to fully solubilise all reactants), catalyst 1a showed suppressed deuteration in positions $a-c$, and enhanced deuteration at position $d$ (Entry 3 ). ${ }^{17}$ Pleasingly and to excellently exemplify the effectiveness of the larger anionic counterion, especially with more demanding pharmaceutically-related substrates, catalyst 1d in 2MeTHF showed improved labelling in all four positions over all other conditions tested (Entry 4 versus 1-3).

\section{Table 2 Improved deuterium labelling of Niclosamide with $\mathbf{1 d} .^{\mathrm{a}}$}

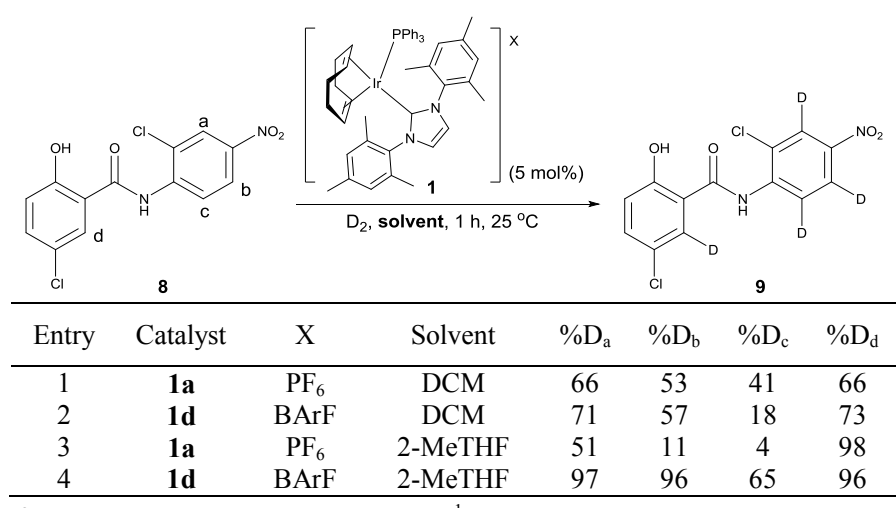

${ }^{a}$ Percent deuteration determined by ${ }^{1} \mathrm{H}$ NMR.

\section{Conclusions}

In summary, we have reported on the syntheses of three novel complexes of the type [(COD)Ir(IMes) $\left.\left(\mathrm{PPh}_{3}\right)\right] \mathrm{X}\left(\mathrm{X}=\mathrm{BF}_{4}\right.$, OTf, and $\mathrm{BArF}$ ), with the BArF complex having been accessed by a modified and more direct preparative process. Application of these complexes as catalysts in hydrogen isotope exchange has demonstrated improved catalytic activity at lower catalyst loadings in the order $\mathrm{X}=\mathrm{BArF} \approx$ OTf $>\mathrm{PF}_{6}>\mathrm{BF}_{4}$. Relative to the parent complex $\left(\mathbf{1 a}, \mathrm{X}=\mathrm{PF}_{6}\right), \mathbf{1 d}(\mathrm{X}=$ $\mathrm{BArF}$ ) possesses a superior solubility profile and applicable solvent scope in HIE processes. This is of fundamental importance to the delivery of labelled drug candidates for use in absorption, distribution, metabolism, excretion, and toxicology (ADMET) studies. Accordingly, the complex 1d now provides a catalyst system of wider potential applicability and effectiveness, in particular, within pharmaceutical settings. Further and in relation to this, the utility of improved solvent 
scope has been demonstrated through improved global deuterium labelling of the drug molecule Niclosamide in 2-MeTHF. Our on-going efforts in this area are focused on the further application of optimal catalyst, 1d, in labelling processes and to alternative $\mathrm{C}-\mathrm{H}$ activation methodologies beyond HIE.

We would like to thank the Carnegie Trust (M.R) for funding. Mass spectrometry data were acquired at the EPSRC UK National Mass Spectrometry Facility at Swansea University.

\section{Notes and references}

${ }^{a}$ Department of Pure and Applied Chemistry, WestCHEM, University of Strathclyde, Glasgow G1 1XL, Scotland, United Kingdom; Tel: (+44)141-548-2959; Fax: (+44)-141-548-4822; E-mail: w.kerr@strath.ac.uk.

$\dagger$ Electronic Supplementary Information (ESI) available: Details of all experimental procedures (catalyst syntheses and deuterium labelling) are provided. For crystallographic data in CIF or other electronic format, see DOI: $10.1039 / \mathrm{c} 000000 \mathrm{x} /$

- Crystallographic data (excluding structure factors) for the new complexes reported in this paper have been deposited with the Cambridge Crystallographic Data Centre as supplementary publications CCDC 1001847 (1b), 1001848 (1c), 1001849 (1d), and 1001850 (4). Copies of the data can be obtained free of charge on application to CCDC, 12 Union Road, Cambridge CB2 1EZ, UK (fax: (+44) 1223-336-033; email: deposit@ccdc.cam.ac.uk) or via www.ccdc.cam.ac.uk/data request/cif.

1 (a) A. Macchioni, Chem. Rev., 2005, 105, 2039; (b) P. S. Pregosin, P. G. A. Kumar and I. Fernández, Chem. Rev., 2005, 105, 2977; (c) I. Krossing and A. Reisinger, Coord. Chem. Rev., 2006, 250, 2721; and references therein.

2 (a) A. Macchioni, G. Bellachioma, G. Cardaci, M. Travaglia and C. Zuccaccia, Organometallics, 1999, 18, 3061; (b) L. A. Evans, N. Fey, J. N. Harvey, D. Hose, G. C. Lloyd-Jones, P. Murray, A. G. Orpen, R. Osborne, G. J. J. Owen-Smith and M. Purdie, J. Am. Chem. Soc., 2008, 130, 14471.

3 C. Moreau, C. Hague, A. S. Weller and C. G. Frost, Tetrahedron Lett., 2001, 42, 6957.

4 (a) A. Lightfoot, P. Schnider and A. Pfaltz, Angew. Chem. Int. Ed. 1998, 37, 2897; (b) S. P. Smidt, N. Zimmermann, M. Studer and A. Pfaltz, Chem. Eur. J., 2004, 10, 4685; (c) L. D. Vázquez-Serrano, B. T. Owens and J. M. Buriak, Inorg. Chim. Acta, 2006, 359, 2786; (d) D. J. Nelson, B. J. Truscott, J. D. Egbert and S. P. Nolan, Organometallics, 2013, 32, 3769.

5 (a) J. Powell, A. Lough and T. Saeed, J. Chem. Soc., Dalton Trans., 1997, 4137; (b) A. R. O’Connor, P. S. White and M. Brookhart, Organometallics, 2010, 29, 5382; (c) D. H. T. Phan, B. Kim and V. M. Dong, J. Am. Chem. Soc., 2009, 131, 15608; (d) S. Moret, R. Dallanegra, A. B. Chaplin, T. M. Douglas, R. M. Hiney and A. S. Weller, Inorg. Chim. Acta, 2010, 363, 574.

6 (a) A. H. Roy and J. F. Hartwig, Organometallics, 2004, 23, 194; (b) L. N. Appelhans, D. Zuccaccia, A. Kovacevic, A. R. Chianese, J. R. Miecznikowski, A. Macchioni, E. Clot, O. Eisenstein and R. H. Crabtree, J. Am. Chem. Soc., 2005, 127, 16299.

7 P. W. Davies and N. Martin, Org. Lett., 2009, 11, 2293.
8 (a) J. R. Heys, J. Label. Compd. Radiopharm., 2007, 50, 770; (b) J. Atzrodt, V. Derdau, T. Fey and J. Zimmermann, Angew. Chem. Int. Ed., 2007, 46, 7744; (c) G. N. Nilsson and W. J. Kerr, J. Label. Compd. Radiopharm., 2010, 53, 662; (d) R. Salter, J. Label. Compd. Radiopharm., 2010, 53, 645; (e) P. H. Allen, M. J. Hickey, L. P. Kingston and D. J. Wilkinson, J. Label. Compd. Radiopharm., 2010, 53, 731; (f) W. J. S. Lockley, A. McEwen and R. Cooke, J. Label. Compd. Radiopharm., 2012, 55, 235; (g) E. M. Isin, C. S. Elmore, G. N. Nilsson, R. A. Thompson and L. Weidolf, Chem. Res. Toxicol., 2012, 25, 532.

9 (a) J. A. Brown, S. Irvine, A. R. Kennedy, W. J. Kerr, S. Andersson and G. N. Nilsson, Chem. Commun. 2008, 1115; (b) A. R. Cochrane, C. Idziak, W. J. Kerr, B. Mondal, L. C. Paterson, T. Tuttle, S. Andersson and G. N. Nilsson, Org. Biomol. Chem., 2014, 12, 3526; (c) J. A. Brown, A. R. Cochrane, S. Irvine, W. J. Kerr, B. Mondal, J. A. Parkinson, L. C. Paterson, M. Reid, T. Tuttle, S. Andersson and G. N. Nilsson, Submitted, 2014.

10 Catalyst 1a is available commercially from Strem Chemicals, Ltd.

11 D. Hesk, P. R. Das and B. Evans, J. Label. Compd. Radiopharm., 1995, 36, 497.

12 R. A. Kelly III, H. Clavier, S. Giudice, N. M. Scott, E. D. Stevens, J. Bordner, I. Samardjiev, C. D. Hoff, L. Cavallo and S. P. Nolan, Organometallics, 2008, 27, 202.

13 For the application of complex 2 in HIE processes, see: (a) A. R. Cochrane, S. Irvine, W. J. Kerr, M. Reid, S. Andersson and G. N. Nilsson, J. Label. Compd. Radiopharm., 2013, 56, 451; (b) W. J. Kerr, M. Reid and T. Tuttle, Submitted, 2014.

14 (a) J. Passays, T. Ayad, V. Ratovelomanana-Vidal, A.-C. Gaumont, P. Jubault and E. Leclerc, Tetrahedron Asymm., 2011, 22, 562; (b) J.-Q. Li and P. G. Andersson, Chem. Commun., 2013, 49, 6131.

15 E. Martìnez-Viviente and P. S. Pregosin, Inorg. Chem., 2003, 42, 2209.

16 For information on the fundamentals of green chemistry and the impact of solvents on pharmaceutical organic synthesis, see: (a) J. L. Tucker, Org. Process Res. Dev., 2006, 10, 315; (b) D. J. C. Constable, C. Jimenez-Gonzalez and R. K. Henderson, Org. Process Res. Dev. 2007, 11, 133; (c) R. A. Sheldon, Chem. Soc. Rev., 2012, 41, 1437.

17 The increased selectivity for position $d$ when using 1a in 2-MeTHF may be based on the increased polarity of the solvent relative to DCM and the resultant increase in competition between substrate and solvent for coordination to iridium. Coordination of the amide carbonyl and labelling via a 5 -membered metallacycle (position $d$ ) is more facile than via the 6-membered metallacycle (position $c$; see ref. 9 for details). Additionally, coordination through the nitro group (for labelling at $a$ and $b$ ) is presumed to be weaker than for the amide. For a recent discussion on the use of coordinating additives to increase reaction chemoselectivity, see: R. M. Drost, T. Bouwens, N. P. van Leest, B. de Bruin and C. J. Elsevier, ACS Catal., 2014, 4, 1349. 


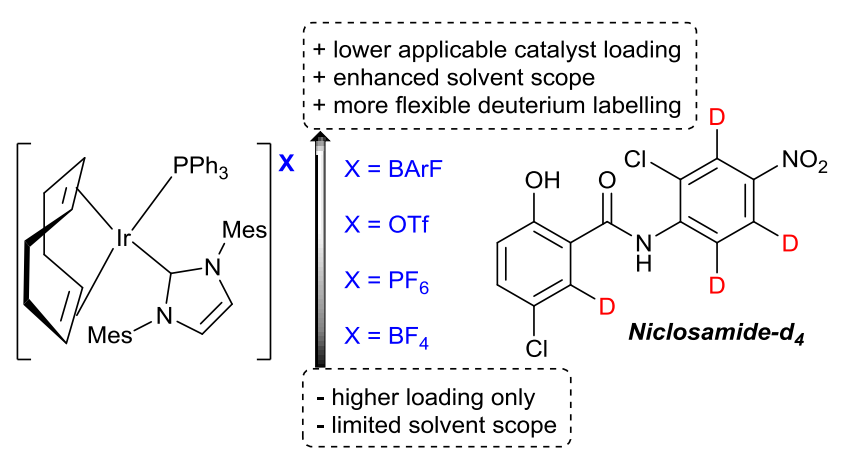

